\title{
Melanogenesis Inhibitory Activity of Rhododendron weyrichii in Mouse B16 Melanoma Cells
}

\author{
MIN-JIN KIM ${ }^{1}$, SANG SUK KIM², SUK HYUN YUN², SEUNG-YOUNG KIM², \\ KWANG HEE HYUN ${ }^{4}$, JUYEONG LEE ${ }^{1}$, NAM HO LEE ${ }^{1}$ and CHANG-GU HYUN ${ }^{1 *}$
}

\author{
${ }^{1}$ Cosmetic Sciences Center, Department of Chemistry and Cosmetics, \\ Jeju National University, Jeju 63243, Korea. \\ ${ }^{2}$ Citrus Research Institute, National Institute of Horticulture and Herbal Science, \\ RDA, Seogwipo 63607, Korea. \\ ${ }^{3}$ Department of BT-Convergent Pharmaceutical Engineering, \\ Sun Moon University, Chungnam 31460, Korea. \\ ${ }^{4}$ Helios Co., Ltd., Sanchundan Dong-gil 16, Jeju 63243, Korea \\ ${ }^{*}$ Corresponding author E-mail: cghyun @ jejunu.ac.kr \\ http://dx.doi.org/10.13005/ojc/320416
}

(Received: April 07, 2016; Accepted: July 08, 2016)

\begin{abstract}
In this study, to evaluate the usefulness of Rhododendron weyrichii Maxim. as a whitening agent, the whitening effects of its extracts were investigated in alpha-melanocyte-stimulating hormone $(\alpha-\mathrm{MSH})$-induced B16F10 melanoma cells. No toxicity was noted in either B16F10 melanoma cells or HaCaT keratinocyte cells that were exposed to the hot water or $70 \%$ ethanol extracts of $R$. weyrichii Maxim. (RW-H and RW-E, respectively). Moreover, both the RW-H and RW-E extracts dose-dependently inhibited $\alpha-\mathrm{MSH}$-induced melanin production in B16F10 melanoma cells, with inhibitory effects of $52.5 \%$ and $51.6 \%$, respectively, at a concentration of $200 \mu \mathrm{g} / \mathrm{mL}$. The RW-H and RW-E extracts also inhibited intracellular tyrosinase activity in a dose-dependent fashion. Western blot analyses showed that the RW-H and RW-E extracts decreased tyrosinase, tyrosinase-related protein-1, and tyrosinase-related protein-2 expression. Additionally, we found that ñ-coumaric acidcontaining RW-H and RW-E extracts could be used as hypopigmentation agents since they suppress melanogenesis. Collectively, our results suggest that RW-H and RW-E extracts have the potential to serve as functional cosmetic agents, including whitening agents.
\end{abstract}

Keywords: B16F10 melanoma cell, melanin, melanogenesis, Rhododendron weyrichii Maxim., tyrosinase, whitening.

\section{INTRODUCTION}

Melanin plays an important role in protecting human skin from the harmful effects of ultraviolet radiation from the sun. In addition, melanin determines our phenotypic appearance. Melanin biosynthesis proceeds through a complex series of enzymatic and chemical reactions in melanocytes ${ }^{1-4}$ 
and is regulated by melanogenic factors such as tyrosinase, tyrosinase-related protein-1 (TRP-1), and tyrosinase-related protein-2 (TRP-2) $)^{5}$. Tyrosinase is particularly important as it can catalyze three different reactions, namely the hydroxylation of tyrosine to 3,4-dihydroxyphenylalanine (DOPA), the oxidation of DOPA to DOPA quinone, and the oxidation of 5,6-dihydroxyindole (DHI) to indolequinone $^{6}$. In the absence of thiols, DOPA quinone changes to DOPA chrome and then to $\mathrm{DHI}$ or indole 5,6-quinone 2-carboxylic acid (DHICA). Two additional steps in this melanogenic pathway include the conversion of DOPA chrome to DHICA, which is catalyzed by TRP-2 (DOPA chrome tautomerase), and the oxidation of DHICA, which is catalyzed by TRP-1 (DHICA oxidase). Moreover, microphthalmiaassociated transcription factor (MITF) strongly stimulates tyrosinase, TRP-1, and TRP-2, indicating that it is an important regulator of melanogenesis ${ }^{7-}$ 11 .

Although melanin has mainly photoprotective functions in human skin, the accumulation of an abnormal amount of melanin in different parts of the skin can create differentially pigmented patches, which may be an esthetic problem for some individuals. This phenomenon has encouraged researchers to discover new potent tyrosinase inhibitors that can inhibit tyrosinase activity, and in turn reduce melanogenesis, in order to serve as skin-whitening cosmetics.

Rhododendron weyrichii Maxim. is a deciduous shrub of the Ericaceae family and its only known habitat is Jeju Island in South Korea. Rhododendron plants have been mostly used as folk medicines to treat high blood pressure or increase urine production. For example, the leaves of Rhododendron schlippenbachii and Rhododendron yedoense var. poukhanense have been used to treat the early symptoms of hypertension, while the leaves of Rhododendron brachycarpum have been used as a diuretic ${ }^{12}$. However, the pharmacological effects of $R$. weyrichii Maxim. have not been examined scientifically. Therefore, in the present study, we verified the pharmacological whitening effects of $R$. weyrichii Maxim. in á-MSH-induced B16F10 murine melanoma cells.

\section{MATERIALS AND METHODS}

\section{Plant material}

R. weyrichii Maxim. flowers were collected from Jeju National University in May, 2015. The materials for extraction were freeze-dried, and then ground into a fine powder by using a blender. The dried powder $(1 \mathrm{~kg})$ was extracted with hot water (water, $1 \mathrm{~L}$ ) at $70^{\circ} \mathrm{C}$ for $4 \mathrm{~h}$ (hot-water extract $[\mathrm{RW}-\mathrm{H}])$, and then evaporated under a vacuum. All other extracts (EtOH extracts [RW-E]; $1 \mathrm{~L}, 1 \mathrm{~kg}$ ) except the RW-H extracts were extracted at room temperature for 2 days. The yield of the $\mathrm{RW}-\mathrm{H}, 20 \%$, $50 \%, 70 \%$, and $100 \% \mathrm{RW}-\mathrm{E}$ extracts were $14.4 \%$, $39.6 \%, 30.1 \%, 22 \%$, and $17.6 \%$, respectively.

\section{Cell culture}

The B16F10 murine melanoma cell line was purchased from the Korean Cell Line Bank (Seoul, Korea). These cells were maintained at sub-confluence in a $95 \%$ air $/ 5 \% \mathrm{CO}_{2}$ humidified atmosphere at $37^{\circ} \mathrm{C}$. The medium used for the routine subculture was Dulbecco's modified Eagle's medium containing $10 \%$ fetal bovine serum, penicillin (100 units $/ \mathrm{mL})$, and streptomycin $(100 \mu \mathrm{g} / \mathrm{mL})$.

\section{MTT assay}

Cell viability was determined using 3-(4,5Dimethylthiazol-2-yl)-2,5-Diphenyltetrazolium Bromide (MTT) assays ${ }^{13,14}$. B16F10 cells were cultured in 24-well plates for $18 \mathrm{~h}$, followed by treatment with various concentrations $(200,400$, and $800 \mu \mathrm{g} / \mathrm{mL}$ ) of the $R$. weyrichii Maxim. extracts for $48 \mathrm{~h}$. Briefly, MTT was added to the cells and the formazan crystals were dissolved in dimethyl sulfoxide. The absorbance was measured at 540 $\mathrm{nm}$. The percentage of cells showing cytotoxicity was determined relative to that in the control group.

\section{Measurement of melanin content}

The amount of melanin in B16F10 cells was measured according to a previously published method $^{15}$ with slight modifications. The cells were treated with the $R$. weyrichii Maxim. extracts and á-MSH for $48 \mathrm{~h}$ at $37^{\circ} \mathrm{C}$. After removing the media, the cells were washed with cold phosphatebuffered saline and the cell pellets were dissolved in $1 \mathrm{M} \mathrm{NaOH}$ for $1 \mathrm{~h}$ at $80^{\circ} \mathrm{C}$. Spectrophotometric 
analysis of the melanin content was performed at an absorbance of $405 \mathrm{~nm}$. Each experiment was performed in triplicate.

\section{Intercellular tyrosinase activity}

Intercellular tyrosinase activity was determined using methods described previously with slight modifications ${ }^{15}$. Here, arbutin was used as a positive control. Briefly, B16F10 cells $\left(1.0 \times 10^{5}\right)$ were seeded in a $60-\mathrm{mm}$ dish, and then the plates were incubated at $37^{\circ} \mathrm{C}$ in a humidified atmosphere of $5 \% \mathrm{CO}_{2}$ for 3 days. Next, seeded B16F10 cells were lysed with phosphate buffer containing $1 \%$ Triton $\mathrm{X}-100$. The lysates were clarified by centrifugation for $15 \mathrm{~min}$ at $13,000 \mathrm{rpm}$. After quantifying the protein levels and adjusting the concentrations using lysis buffer, we added each lysate, which contained identical amounts of protein, and placed the indicated concentrations of the test samples into a 96-well plate; then, $15 \mathrm{mM}$ L-DOPA was added per well. After incubation at $37^{\circ} \mathrm{C}$, we measured the absorbance at a wavelength of $475 \mathrm{~nm}$ using an enzyme-linked immunosorbent assay reader.

\section{Western blot analysis}

After the $\alpha$-MSH-induced B16F10 cells were incubated for $48 \mathrm{~h}$, the cells were washed twice with cold phosphate-buffered saline. The cells were allowed to lyse in lysis buffer (radioimmunoprecipitation assay buffer, $1 \%$ Nonidet P-40, 1\% protease inhibitor cocktail) for $1 \mathrm{~h}$, and were then collected in microtubes and centrifuged at $15,000 \mathrm{rpm}$ for $15 \mathrm{~min}$ at $4^{\circ} \mathrm{C}$. The supernatants were prepared in new microtubes. The protein content of the cell lysates was determined with Bradford reagent (Bio-Rad) using bovine serum albumin as the standard. After heating at $70^{\circ} \mathrm{C}$ for $10 \mathrm{~min}$, equal amounts of the cell lysates were separated with $4 \sim 12 \%$ Bis-Tris mini gel electrophoresis (Invitrogen Inc.) and transferred to a nitrocellulose membrane (Invitrogen Inc.). The membrane was then washed with Tris-buffered saline (TBS; $20 \mathrm{mM}$ Tris base, $137 \mathrm{mM} \mathrm{NaCl}, \mathrm{pH} 7.6$ ) containing $0.1 \%$ Tween 20 (TTBS) and blocked in TTBS containing 5\% skim milk solution for $24 \mathrm{~h}$. The membrane was incubated overnight at $4^{\circ} \mathrm{C}$ with the primary antibodies diluted in TTBS (1:1000). Primary antibodies (TRP-1,

(A)

(B)
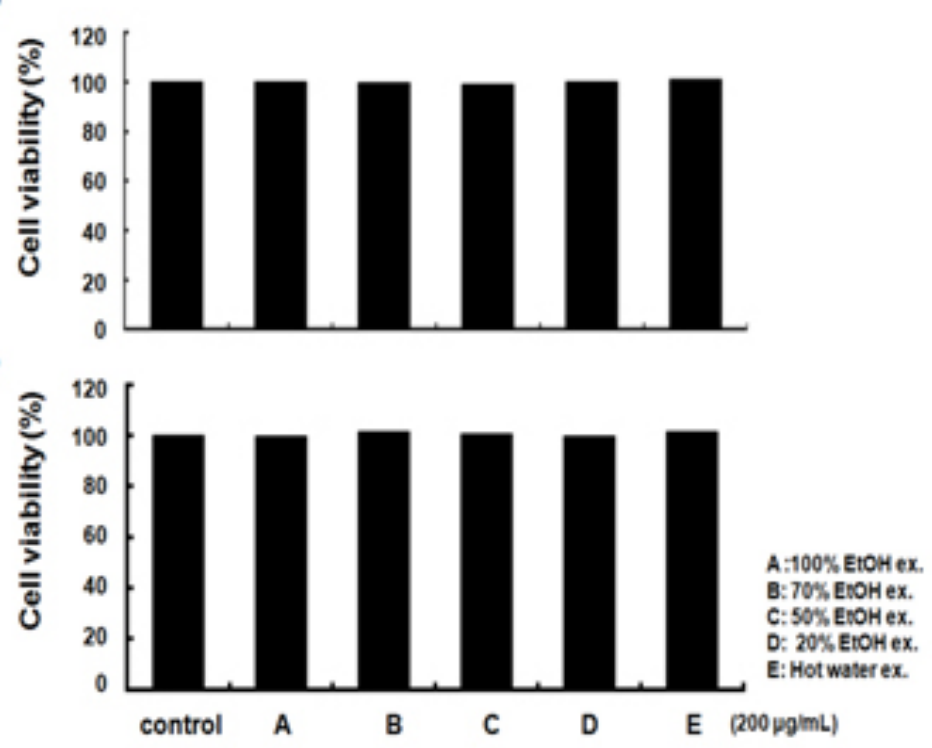

An MTT assay was performed after incubating the HaCaT and B16F10 cells with the R. weyrichii Maxim. extracts for $24 \mathrm{~h}$ at $37^{\circ} \mathrm{C}$ in a $5 \% \mathrm{CO} 2$ atmosphere. Cell viability in (A) HaCaT cells and (B) B16F10 cells. Absorbance was measured at $540 \mathrm{~nm}$.

Fig. 1: Effects of the Rhododendron weyrichii Maxim. extracts on the cell viability of $\mathrm{HaCaT}$ and B16F10 cells 
TRP-2, tyrosinase) were purchased from Santa Cruz Inc. Membranes were washed four times with TTBS. Then, each membrane was incubated for
$1 \mathrm{~h}$ with secondary peroxidase-conjugated goat immunoglobulin $\mathrm{G}$ (1:5000) and washed four times with TTBS. The target proteins were detected using
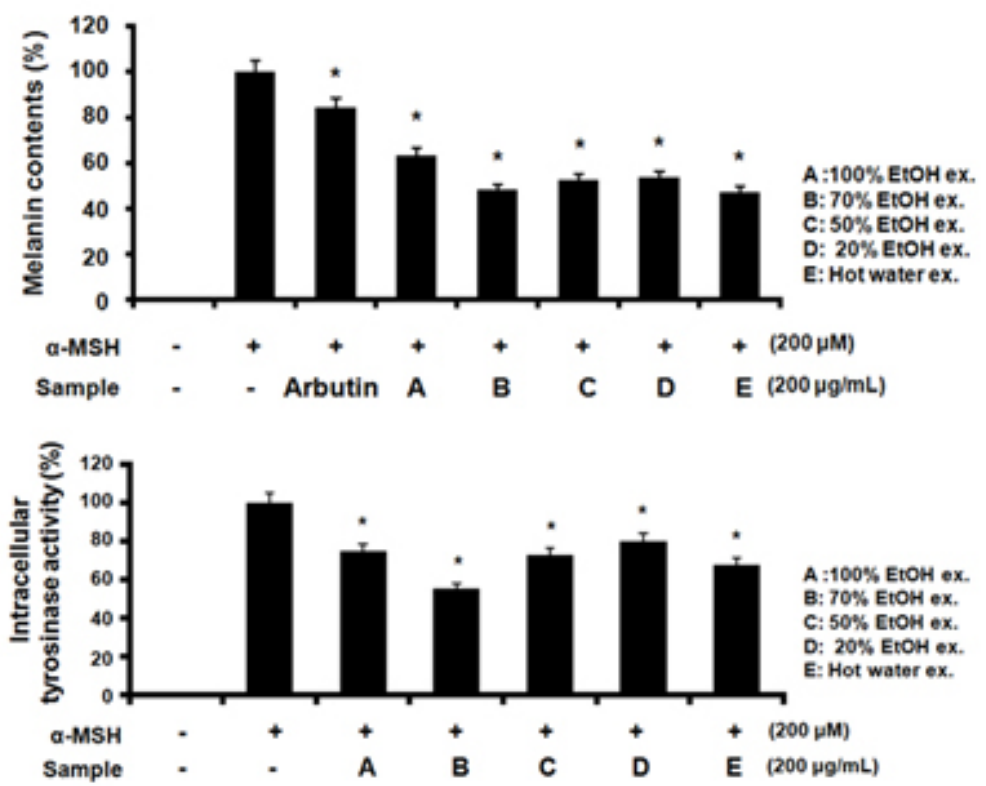

B16F10 cells $\left(2.0 \times 10^{4}\right)$ were pre-incubated for $18 \mathrm{~h}$ and the melanin content was examined in B16F10 cells treated with $\alpha-\mathrm{MSH}(200 \mathrm{nM})$, arbutin $(100 \mu \mathrm{M})$, and the $R$. weyrichii Maxim. extracts for $72 \mathrm{~h}$ at $37^{\circ} \mathrm{C}$ in a $5 \% \mathrm{CO}_{2}$ atmosphere. The melanin content $(\mathrm{A})$ and cellular tyrosinase activity (B) were measured as described in the "Materials and methods" section.

Fig. 2: Inhibitory effects of Rhododendron weyrichii Maxim. extracts on melanogenesis and intracellular tyrosinase activity in B16F10 cells

A.

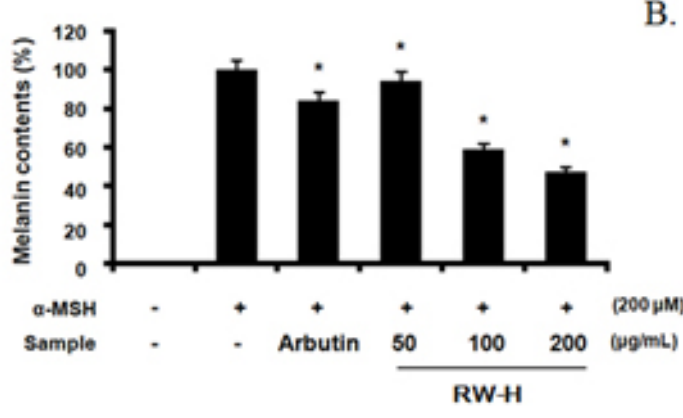

B.

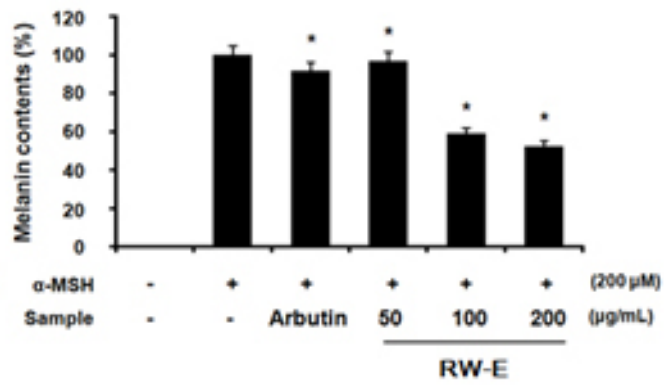

B16F10 cells $\left(2.0 \times 10^{4}\right)$ were pre-incubated for $18 \mathrm{~h}$ and the melanin content was examined in B16F10 cells treated with $\alpha-\mathrm{MSH}(200 \mathrm{nM})$, arbutin $(100 \mu \mathrm{M})$, and the $R$. weyrichii Maxim. hot water $(\mathrm{RW}-\mathrm{H})$ and $\mathrm{EtOH}$ (RW-E) extracts for $72 \mathrm{~h}$ at $37^{\circ} \mathrm{C}$ in a $5 \% \mathrm{CO}_{2}$ atmosphere. The melanin content was measured as described in the "Materials and methods" section.

Fig. 3: Inhibitory effects of Rhododendron weyrichii Maxim. extracts on melanogenesis in B16F10 cells 
an enhanced chemiluminescence solution. The immunoreactive bands were detected and exposed to X-ray film. Protein levels were quantified by scanning the immunoblots.

\section{High-performance liquid chromatography analysis}

High-performance liquid chromatography (HPLC) was performed with a Waters 2695 chromatograph system (Waters, Milford, MA, USA), which included a Waters 2489 UV visible detector. Utilizing a YMC ProC18 column $(250 \times 4.6 \mathrm{~mm})$ was used to separate Á-coumaric acid from RW-H and $\mathrm{RW}-\mathrm{E}$ extracts. The mobile phase of quantitative analysis was a mixture of water-methanol-glacial acetic acid (80:18:2). The injection volume of the sample was $10 \mathrm{iL}$. The flow rate was kept at 0.6 $\mathrm{mL} / \mathrm{min}$ and detection of the Á-coumaric acid was performed at $320 \mathrm{~nm}$. All solutions, including samples (RW-H and RW-E extracts) and standard (Á-coumaric acid), were filtered through a 0.45 -ìm membrane before being directly injected into the HPLC system.

\section{Statistical analysis}

All data were obtained in triplicate and are presented as the mean \pm the standard error of the mean. Significant differences between treatments were determined with Student's $t$-tests in one-way analyses of variance.

\section{RESULTS}

Effects of R. weyrichii Maxim. extracts on B16F10 melanoma cell viability and $\mathrm{HaCaT}$ keratinocyte cell cytotoxicity

To evaluate the effects of the $R$. weyrichii Maxim. extracts on cell viability, we treated B16F10 melanoma cells with the RW-H extract and various concentrations of the RW-E extract, and then measured the cell viability using an MTT assay. As shown in Fig. $1 \mathrm{~A}$, none of the extracts at concentrations of up to $200 \mathrm{ig} / \mathrm{mL}$ had significant effects on the cell viability of B16F10 melanoma cells when compared to untreated control cells after $48 \mathrm{~h}$.

In addition, to determine the effects of these extracts on skin-related cells, the cytotoxicity of the extracts toward human $\mathrm{HaCaT}$ keratinocyte cells was examined under the same conditions as those for the B16F10 melanoma cells. As shown in Fig. 1B, none of the extract concentrations used in this study had cytotoxic effects on $\mathrm{HaCaT}$ keratinocyte cells. These results indicate that the RW-H and RW-E extracts are safe for human skin cells at these concentrations. Based on the results of the cell viability experiments, the concentration of $200 \mathrm{ig} / \mathrm{mL}$ was used in the remaining experiments.
A.

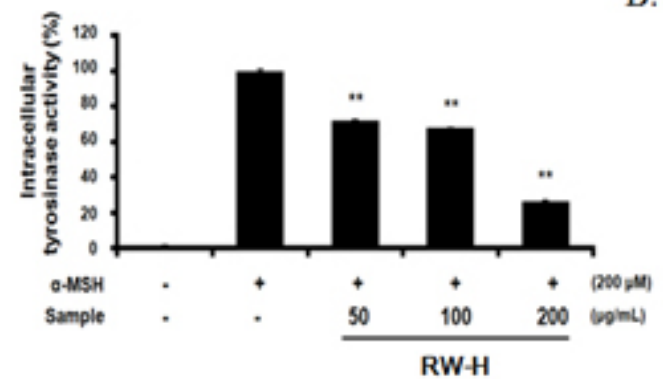

B.

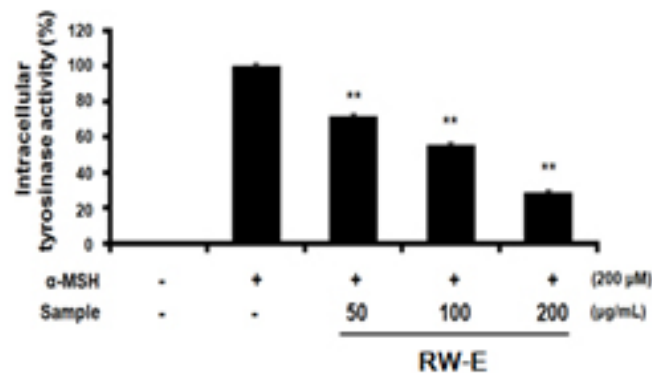

B16F10 cells $\left(2.0 \times 10^{4}\right)$ were pre-incubated for $18 \mathrm{~h}$ and the melanin content was examined in B16F10 cells treated with á-MSH (200 nM) and the R. weyrichii Maxim. hot water (RW-H) and EtOH (RW-E) extracts for $72 \mathrm{~h}$ at $37^{\circ} \mathrm{C}$ in a $5 \% \mathrm{CO}_{2}$ atmosphere. The intracellular tyrosinase activity was measured as described in the "Materials and methods" section.

Fig. 4: Inhibitory effects of Rhododendron weyrichii Maxim. extracts on intracellular tyrosinase activity in B16F10 cells 
Effects of $\boldsymbol{R}$. weyrichii Maxim. extracts on melanin content and intracellular tyrosinase activity in B16F10 melanoma cells

Next, we investigated the effects of the $\mathrm{RW}-\mathrm{H}$ and RW-E extracts on the $\alpha-\mathrm{MSH}$-induced melanin content in B16F10 melanoma cells. Cells treated with á-MSH alone had markedly increased melanin content compared to untreated cells. All $\mathrm{RW}-\mathrm{H}$ and RW-E extracts $(200 \mu \mathrm{g} / \mathrm{mL})$ significantly inhibited the melanin content better than did arbutin (Fig. 2A).

The observed suppression of the melanin indicates that they are associated with the activity of the enzyme involved in melanin synthesis. Tyrosinase is the rate-limiting step (reaction ratedetermining step) in the melanin synthesis process and is responsible for the first stage of melanin biosynthesis ${ }^{16}$. This suggests that inhibiting the activity of tyrosinase may also inhibit melanin synthesis. Therefore, we examined whether the

A.

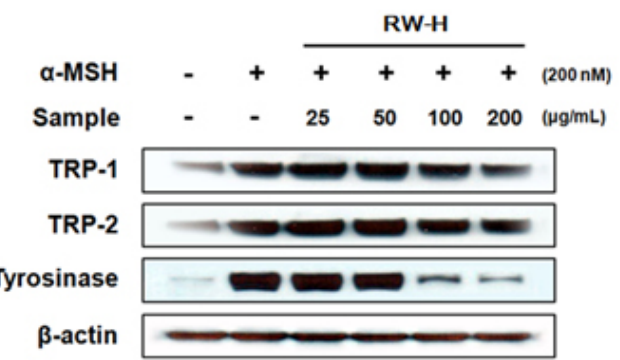

B.
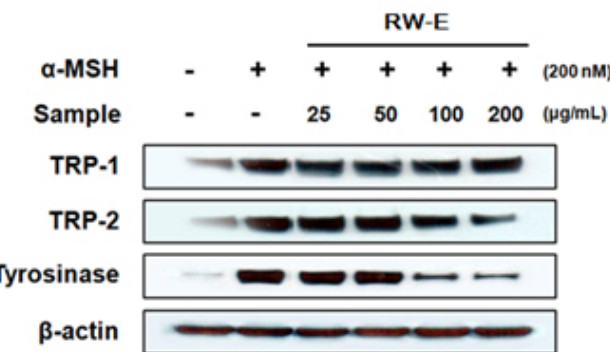

B16F10 cells $\left(1.0 \times 10^{5}\right.$ cells $\left./ \mathrm{mL}\right)$ were preincubated for $18 \mathrm{~h}$, and the cells were stimulated with á-MSH (200 nM) and the R. weyrichii Maxim. hot water $(\mathrm{RW}-\mathrm{H})$ and EtOH (RW-E) extracts for $24 \mathrm{~h}$. The expression level was determined using immunoblotting methods.

Fig. 5: Inhibitory effects of Rhododendron weyrichii Maxim. extracts on the levels of tyrosinase, TRP-1, and TRP-2 in á-MSH-induced B16F10 cells
RW-H and RW-E extracts would affect the activity of tyrosinase by treating B16F10 cells with the extracts and measuring the tyrosinase activity. The extracts inhibited tyrosinase to a degree that was similar to the amount of melanin synthesis (Fig. 2B).

Thus, the RW-H and RW-E extracts inhibited the melanin content and intercellular tyrosinase activity. Since the experiment was performed by selecting the RW-H and $70 \% \mathrm{RW}-\mathrm{E}$ extracts, we next examined their potential as cosmetic raw materials.

Effects of RW-H and RW-E on the melanin content and intracellular tyrosinase activity in B16F10 melanoma cells

As mentioned above, neither the RW-H nor RW-E extracts were toxic to B16F10 cells at concentrations of $50 \mu \mathrm{g} / \mathrm{mL}$ to $200 \mu \mathrm{g} / \mathrm{mL}$ (Fig. 1).

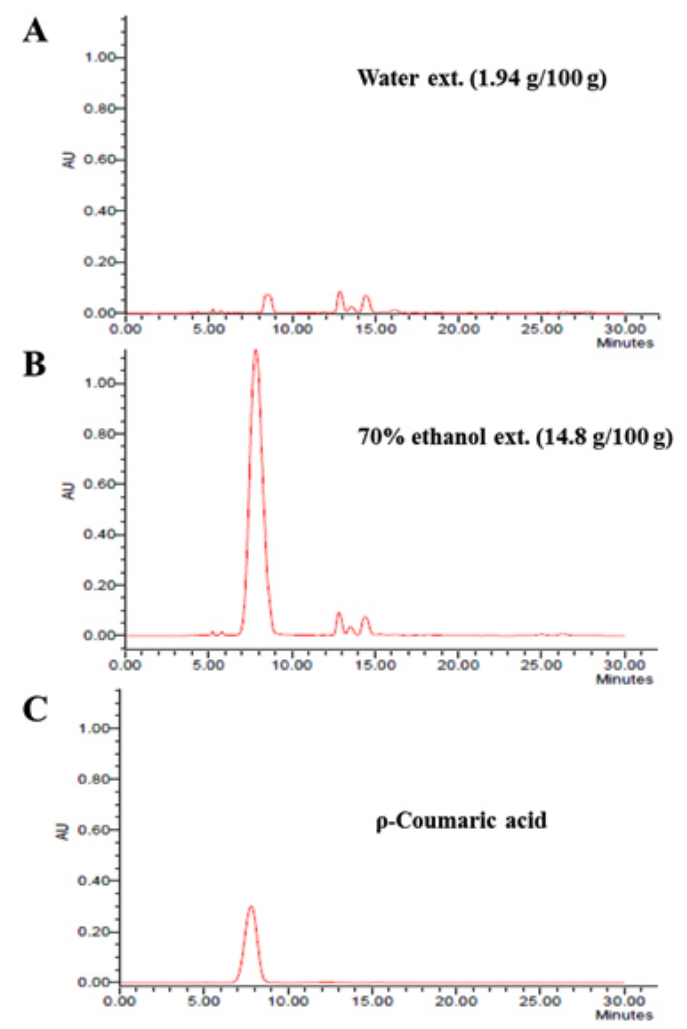

The lower side $(C)$ represents standard $\rho$-coumaric acid. The wavelength of $\rho$-coumaric acid absorbance is $320 \mathrm{~nm}$.

Fig. 6: HPLC fingerprinting analysis of the R. weyrichii water $(A)$ and $70 \%$ ethanol (B) extracts 
Next, we explored the effects of the RW-H and RW-E extracts on $\alpha-\mathrm{MSH}$-induced melanin synthesis and tyrosinase activity. As shown in Fig. 3, cells treated with $\alpha-\mathrm{MSH}$ alone had markedly increased melanin content compared to normal cells. Arbutin, a potent inhibitor in standard skin-whitening agents, was used as a positive control. RW-H and RW-E extracts $(200 \mu \mathrm{g} / \mathrm{mL})$ clearly inhibited melanin synthesis more than did arbutin. In fact, the RW-H and RW-E extracts dose-dependently inhibited á-MSH-induced melanin production in B16F10 melanoma cells, with inhibitory effects of $52.5 \%$ and $51.6 \%$, respectively, at a concentration of $200 \mu \mathrm{g} / \mathrm{mL}$.

Moreover, because melanin synthesis is ultimately regulated by tyrosinase, the direct inhibitory effects of the RW-H and RW-E extracts on tyrosinase were examined in B16F10 melanoma cells using intercellular tyrosinase assays. As shown in Fig. 4, the RW-H and RW-E extracts decreased the activity of intercellular tyrosinase in a concentrationdependent manner.

Effects of RW-H and RW-E on melanogenesisrelated proteins in B16F10 melanoma cells

The above results suggest that the RW-H and RW-E extracts have inhibitory effects on melanin generation, as the extracts inhibited the tyrosinase activity in B16F10 cells. Thus, we next investigated whether the anti-melanogenic effects of the RW-H and RW-E extracts exert their whitening activity by inhibiting protein expression or function at any other steps in the generation process.

After exposing B16F10 cells to the RW-H and RW-E extracts, we confirmed the expression of tyrosinase, TRP-1, and TRP-2, known as the key enzymes/proteins in melanin production, through western blots. As shown in Fig. 5, when the cells were stimulated with á-MSH, a significant increase in tyrosinase was observed, and TRP-1 and TRP-2 expression also increased. Interestingly, as the concentration of the RW-H extract increased, the amount of tyrosinase and TRP-1 expression decreased (Fig. 5A). However, TRP-2 expression did not show a significant change. In contrast, the RW-E extract did not affect the expression of TRP-1 protein, but did inhibit the á-MSH-induced tyrosinase and TRP-2 expression in a dose-dependent manner (Fig. 5B). No changes in the protein levels of $\beta$-actin, a housekeeping protein that was used as an internal control, were observed.

Thus, we investigated the inhibition of tyrosinase, TRP-1, and TRP-2 expression by western blotting to describe the influence of the $\mathrm{RW}-\mathrm{H}$ and RW-E extracts on $\alpha-\mathrm{MSH}$-induced MITF expression.

\section{HPLC fingerprinting analysis of the RW-H and RW-E extracts}

Chromatographic methods (for example, HPLC fingerprinting) can be used to identify the active ingredients of traditional oriental medicines. In the field of natural chemistry, interest in HPLC fingerprinting analysis has increased, both in Asia and globally. Therefore, a simple HPLC fingerprinting method was developed. Because $p$-coumaric acid is reportedly an effective anti-melanogenic agent, it was used as a standard substance. Using HPLC fingerprinting, $p$-coumaric acid was resolved from the $\mathrm{RW}-\mathrm{H}$ and RW-E extracts with clear peak shapes. The $p$-coumaric acid content in the RW-H and RW-E extracts (100 g) was $1.94 \mathrm{~g}$ and $14.8 \mathrm{~g}$, respectively (Fig. 6).

\section{DISCUSSION}

$R$. weyrichii Maxim. is a deciduous shrub that only grows on Jeju Island in South Korea. Rhododendron plants tend to be used as folk medicines to increase urine production or treat high blood pressure. However, the pharmacological effects of $R$. weyrichii Maxim. have not been proven scientifically ${ }^{12}$. Therefore, in the present study, we verified the pharmacological whitening effects of R. weyrichii Maxim. in $\alpha-\mathrm{MSH}$-induced B16F10 melanoma cells.

In this study, we first determined the potential cytotoxicity of all $R$. weyrichii Maxim. extracts on B16F10 melanoma cells and $\mathrm{HaCaT}$ keratinocyte cells by using MTT assays. The results showed that cells retained almost the same viability when exposed to each extract at concentrations of $200 \mu \mathrm{g} / \mathrm{mL}$.

Next, the inhibitory action of each extract on melanogenesis was evaluated. Melanin synthesis is mainly activated by ultraviolet light, which generates 
DNA photoproducts and causes various autocrine and paracrine factors to be secreted. One of the most well known factors is $\alpha-\mathrm{MSH}^{17}$. By inducing melanin synthesis with $\alpha-\mathrm{MSH}$, we investigated how the $R$. weyrichii Maxim. extracts affect melanin formation. We found that cells treated with á-MSH alone had markedly increased melanin content compared to normal cells. All R. weyrichii Maxim. extracts of $\mathrm{RW}$ at a concentration of $200 \mu \mathrm{g} / \mathrm{mL}$ significantly inhibited the melanin content better than did arbutin. Moreover, the degree to which the melanin content was suppressed indicates that the extracts are associated with the enzymatic activity of melanin synthesis.

Tyrosinase catalysis is involved in the first two steps of mammalian melanogenesis, which is the process that produces the dark macromolecular pigment melanin. Over-activity of this enzyme leads to the overproduction of melanin, which in turn produces hyperpigmentation of the skin. Inhibition of tyrosinase can also lead to reduced melanin content. Tyrosinase inhibitors have become increasingly important in medications and cosmetics, as they can prevent hyperpigmentation by inhibiting enzymatic oxidation ${ }^{18,19}$. Therefore, we determined how the Rhododendron weyrichii Maxim. extracts affected the activity of tyrosinase in B16F10 cells. Our results showed that the extracts had inhibitory effects on tyrosinase that were similar to the level of melanin synthesis. Indeed, all extracts examined inhibited the melanin content and intercellular tyrosinase activity.

Next, we selected the RW-H and $70 \%$ RW-E extracts and examined their potential to be developed as cosmetic raw materials. We found that the RW-H and RW-E extracts were not toxic to B16F10 cells at concentrations of 50 to $200 \mu \mathrm{g} / \mathrm{mL}$. We also explored the effects of the RW-H and RW-E extracts on $\alpha-\mathrm{MSH}$-induced melanin synthesis and tyrosinase activity. The RW-H and RW-E extracts $(200 \mu \mathrm{g} / \mathrm{mL})$ clearly inhibited melanin synthesis better than did arbutin. RW-H and RW-E concentrationdependently inhibited $\alpha-\mathrm{MSH}$-induced melanin production in B16F10 melanoma cells (inhibitory effects of $52.5 \%$ and $51.6 \%$, respectively) and decreased the intercellular tyrosinase activity in a concentration-dependent manner.
Melanogenesis is known to be controlled by an enzymatic cascade, which is regulated at the level of tyrosinase, TRP-1, and TRP $-2^{20}$. Thus, to better understand the molecular mechanisms underlying the anti-melanogenic effects of the RW-H and RW-E extracts, we evaluated the expression levels of tyrosinase, TRP-1, and TRP-2. We noted that as the RW-H extract concentration increased the amount of tyrosinase and TRP-1 expression decreased, while the expression level of TRP-2 remained unchanged. On the other hand, the RW-E extract had no effect on TRP-1 expression but did inhibit the expression of $\alpha-\mathrm{MSH}$-induced tyrosinase and TRP-2 in a concentration-dependent manner. The protein level of â-actin, which was used as an internal control, did not change.

MITF is a transcription factor that effectively transactivates tyrosinase and its related genes by binding to their common promoters ${ }^{21}$. Hence, we investigated the inhibition of tyrosinase, TRP-1, and TRP-2 expression by western blotting to describe the influence of the RW-H and RW-E extracts on $\alpha$-MSH-induced MITF expression.

In conclusion, our results suggest that the RW-H and RW-E extracts inhibited melanin production in $\alpha-\mathrm{MSH}$-induced $\mathrm{B} 16 \mathrm{~F} 10$ melanoma cells by suppressing tyrosinase, TRP-1, and TRP-2 expression. Such inhibitory effects indicate that the RW-H and RW-E extracts can influence MITF protein expression. Furthermore, RW-H and RW-E extracts containing p-coumaric acid could be used as hypopigmentation agents given their ability to suppress melanogenesis. Collectively, our results suggest that RW-H and RW-E extracts could be developed into functional cosmetic agents, such as whitening agents.

\section{ACKNOWLEDGEMENTS}

This work was supported by the Academic and Research Institutions R\&D Program (C0268105) funded by the Small and Medium Business Administration (SMBA, Korea). 


\section{REFERENCES}

1. Hearing, V.J.; Körner, A.M.; Pawelek, J.M.; Journal of Investigative Dermatology, 1982, 79, 16-18.

2. Hearing, V.J.; Jiménez, M.; International Journal of Biochemistry, 1987, 19, 11411147.

3. Prota, G.; Medicinal Research Reviews, 1988 , 8, 525-556.

4. Kuzumaki, T.; Matsuda, A.;Wakamatsu, K.; Ito S.; Ishikawa, K.; Experimental Cell Research, 1993, 207, 33-40.

4. Del Marmol, V.; Beermann, F.; FEBS Letters, 1996, 381, 165-168.

5. Ye, Y.; Chu, J.H.; Wang, H.; Xv, H.; Chou, G.X.; Leung, A.K.M.; Fong, W.F.; Yu, Z.L.; Journal of Ethnopharmacology, 2010, 132, 533-535.

6. Jackson, I.J.; Chambers, D.M.; Tsukamoto, K.; Copeland, N.G.; Gilbert, D.J.; Jenkins, N.A.; Hearing, V.J.; EMBO Journal, 1992, 11, 527-535.

7. Park, S.H.; Kim, D.S.; Kim, W.G.; Ryoo, I.J.; Lee, D.H.; Huh, C.H.; Youn, S.W.; Yoo, I.D.; Park, K.C.; Cellular and Molecular Life Sciences, 2004, 61, 2878-2885.

8. Tsukamoto, K.; Jackson, I.J.; Urabe, K.; Montague, P.M.; Hearing, V.J.; EMBO Journal, 1992, 11, 519-526.

9. Matz, H.; Tur, E.; Current Problems in Dermatology, 2007, 35, 78-102.

10. Yoon, W.J.; Ham, Y.M.; Yoon, H.S.; Lee, W.J.; Lee, N.H.; Hyun, C.G.; Natural Product Communications, 2013, 8,1359-1362.
11. Levy, C.; Khaled, M.; Fisher, D.E.; Trends in Molecular Medicine, 2006, 12, 406-414.

12. Choi, J.S.; Young, H.S.; Park, J.C.; Choi, J.H.; Woo, W.S.; Archives of Pharmacal Research, 1986, 9, 233-236.

13. Gerlier, D.; Thomasser, N.; Journal of Immunological Methods, 1986, 94, 57-63.

14. Liu,Y.; Progress in Neuro-Psychopharmacology and Biological Psychiatry, 1996, 23, 377395.

15. Hill, S.E.; Buffey, J.; Thody, A.J.; Oliver, I.; Bleeheb, S.S.; Mac Neil, S.; Pigment Cell Res., 1989, 2,161-166.

16. Halaban, R.; Patton, R.S.; Cheng, E.; Svedine, S.; Trombetta, E.S.; Wahl, M.L.; Ariyan, S.; Hebert, D.N.; J. Biol. Chem., 2002, 277, 14821-14828.

17. Hunt, G.,; Kyne, S.; Ito, S.; Wakamatsu, K.; Todd, C.; Thody, A.; Pigment Cell Res., 1995, 8, 202-208.

18. García-Borron, J.C.; Solano, F.; Pigment Cell Research, 2002, 15, 162-173.

19. Wilcox, D.E.; Porras, A.G.; Hwang, Y.T.; Lerch, K.; Winkler, M.E.; Solomon, E.I.; Journal of the American Chemical Society, 1985, 107:40154027.

20. Gaggioli, C.; Busca, R.; Abbe, P.; Ortonne, J.P.; Ballotti, R.; Pigment Cell Research, 2003, 16, 374-382.

21. Busca, R.; Ballotti, R.; Pigment Cell Research, 2000, 13, 60-69. 